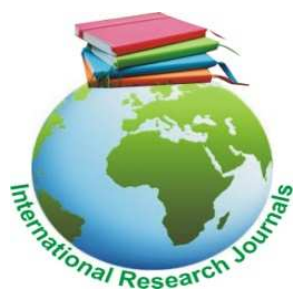

Journal of Medicine and Medical Sciences Vol. 8(7) pp. 095-099, December 2017

DOI: http:/dx.doi.org/10.14303/jmms.2017.187

Available online http://www.interesjournals.org/JMMS

Copyright (C) 2017 International Research Journals

Full Length Research Paper

\title{
Prevalence and characteristics of metabolic syndrome among hypertensive patients attending a tertiary hospital in Kano, Nigeria
}

\author{
${ }^{1}$ Dr Saidu Hadiza* and ${ }^{2}$ Abdulwahab Kabir \\ ${ }^{1}$ Department of Medicine, Bayero University / Murtala Muhammad Specialist Hospital, Kano, Nigeria \\ ${ }^{2}$ Department of Medicine, Murtala Muhammad specialist Hospital, Kano, Nigeria \\ ${ }^{*}$ Corresponding Author's E- mail: hsaidu2006@yahoo.com
}

\begin{abstract}
Hypertension is the most common and important cardiovascular disease (CVD) risk factor, frequently clustering with other risk factors to increase cardiovascular disease morbidity and mortality. This study therefore, aimed to assess the prevalence of metabolic syndrome (MS) among hypertensive subjects using the criteria of the National Cholesterol Education Program's Adult Treatment Panel III(NCEP ATP III)in a tertiary hospital, in Kano, North - Western Nigeria. This was a cross-sectional study conducted at the hypertensive clinic of Murtala Muhammad Specialist Hospital, Kano. Structured pretested interviewer administered questionnaire was used for data collection. A population of 240 hypertensive patients ( 119 males and 121 females) over the age of 18 years were screened for metabolic syndrome by determining the body mass index (BMI), waist circumference, levels of fasting plasma glucose and fasting plasma lipids. Out of the 240 patients studied, 92(38.2\%) patients met the criteria for metabolic syndrome. $26(28.6 \%)$ of them were males and $66(71.4 \%)$ were females. Type II diabetes mellitus was found in $85(35.8 \%)$, impaired fasting glucose in $18(7.5 \%)$, high plasma triglycerides in $\mathbf{5 8}(24.4 \%)$ and low high density lipoprotein cholesterol in $79(33 \%)$.Obesity was found in 105(43.8\%). The prevalence of metabolic syndrome among hypertensives in Kano is high. Therefore, regular screening and control of hypertension and other CVD risk factors is necessary to prevent complications.
\end{abstract}

Keywords: Hypertensives, Metabolic syndrome, Kano, Nigeria.

\section{INTRODUCTION}

Cardiovascular diseases (CVDs) remain the leading cause of death and disability worldwide, with over $80 \%$ of the deaths occurring in the low and middle income countries (WHO Global Report 2011). Although a large proportion of the deaths are preventable, they continue to rise mainly because preventive measures are inadequate. It has been projected that by the year 2030 , about 23.6 million people will die from CVDs (WHO Global Report 2011). This is attributable to the worsening
CVD risks profiles in the developing countries as a result of epidemiologic transition (WHO Global Report 2011).

Metabolic syndrome is characterized by a constellation of CVD risk factors that are metabolic in origin that include artherogenic dyslipidemia, hypertension, obesity, dysglycaemia, insulin resistance and/ hyperinsulinaemia (Miranda et al., 2005). The diagnostic criteria for MS has been published by different Working Groups with modifications and revisions towards 
finding a common ground (Albeti et al., 2009) These diagnostic criteria include World Health Organization (WHO) criteria, The European Group for the study of Insulin Resistance (EGIR) criteria, The American College of Endocrinology (ACE) criteria, the International Diabetes Federation (IDF) criteria and the Third Report of the National Cholesterol Education Programme Adult Treatment Panel (NCEP ATP) III criteria (Albeti et al., 2009; Grundy et al, 2004; Balkas and Charles 1999 et al, 2003; Grundy et al., 2005).

The most widely used clinic - based diagnostic criteria are those of the IDF and NCEP - ATP III. Using the NCEP - ATP III criteria, an individual is considered to have MS in the presence of three of the following clinical criteria. Blood pressure (BP) $\geq 130 / 85 \mathrm{mmHg}$, waist circumference $(\mathrm{WC})>102 \mathrm{~cm}$ in men and $>88 \mathrm{~cm}$ in women, $\mathrm{HDL}$ cholesterol $<1.0 \mathrm{mmol} / \mathrm{l}(40 \mathrm{mg} / \mathrm{dl})$ in men and $<1.3 \mathrm{mmmol} / \mathrm{l}(50 \mathrm{mg} / \mathrm{dl})$ in women, triglycerides (TG) $\geq 1.7 \mathrm{mmol} / \mathrm{L}(150 \mathrm{mg} / \mathrm{dl})$ and $\mathrm{FBG} \geq 5.6 \mathrm{mmol} / \mathrm{l}(101 \mathrm{mg} / \mathrm{dl})$ Grundy et al., 2005).

The syndrome has generated much concern over the past few years because it clearly represents a high risk for developing coronary artery disease and cardiovascular events (Berner et al., 2006).

The aim of this study was to determine the prevalence of this high risk condition in a population of hypertensive patients attending a tertiary hospital in Kano, Nigeria.

\section{MATERIALS AND METHODS}

The study was cross sectional carried out in Murtala Muhammad Specialist Hospital, Kano State, Nigeria. The study protocol was approved by the research and ethics committee of the hospital, before commencement of the study. The study population comprised of 240 hypertensive subjects (males 117; females 123) aged at least 18 years, attending the hypertensive clinic of the hospital. The patients were consecutively selected from the male and female hypertensive clinics and screened for the presence of metabolic syndrome from July to September, 2017.

Structured pre-tested interviewer administered questionnaire, which included personal data, history of type II diabetes mellitus, measurement of body mass index (BMI), waist circumference, fasting plasma glucose and fasting lipid profile (TG, total cholesterol, high density lipoprotein cholesterol, $\mathrm{HDL}-\mathrm{C}$ ) was used for data collection.

The diagnosis of metabolic syndrome was based on the NCEP - ATPIII criteria (Grundy et al., 2005). A patient was considered obese if $B M I$ was $\geq 30 \mathrm{Kg} / \mathrm{m}^{2}$, and a diagnosis of abdominal obesity was made when the waist circumference exceeded $102 \mathrm{~cm}$ (40 inches) in males and $88 \mathrm{~cm}$ (35 inches) in females (Daubresse et al., 2000). Dyslipidemia was defined using the National Cholesterol Education Programme - Adult Treatment Panel III (NCEP ATP III) guidelines (NCEP - ATP III, 2002). Hypercholesterolemia was diagnosed when total cholesterol (TC) $\geq 200 \mathrm{mg} / \mathrm{dl} \quad(5.2 \mathrm{mmol} / \mathrm{L})$, hypertriglyceridemia when triglycerides $(T G) \geq 150 \mathrm{mg} / \mathrm{dl}$ $(3.38 \mathrm{mmol} / \mathrm{L})$ and low high density lipoprotein cholesterol $(\mathrm{HDL}-\mathrm{C}) \leq 40 \mathrm{mg} / \mathrm{dl}(1.0 \mathrm{mmol} / \mathrm{L})$ in men or if $\leq 50 \mathrm{mg} / \mathrm{dl}$ (1.2mmol/L) in women (NCEP - ATP III, 2002). DM and impaired fasting glucose was diagnosed in accordance with the American Diabetes Association guidelines (Report of the expert committee on the diagnosis and classification of Diabetes Mellitus, 2002).

All laboratory tests were done in the chemical pathology laboratory of Murtala Muhammad Specialist Hospital, using the auto-analyzer machine (Chiron Diagnostic- Bayer, England, 2009).

The statistical analysis was conducted using SPSS version 19 (Chicago, IL, USA). Continuous variables were presented as mean \pm standard deviation. Qualitative variables were expressed as proportions and percentages. The Chi-squared or Fisher's Exact tests were used to compare proportions, while Student's t-test was used to compare means. A $P$ value $<0.05$ was considered significant.

\section{RESULTS}

Of the 240 hypertensive patients, $92(38.2 \%)$ met the ATP III criteria for the diagnosis of MS. This comprised of 66 males and 26 females giving prevalence of $71.4 \%$ and $28.6 \%$ respectively. The mean age of the patients was $56 \pm 11.8$ years with a range of 24 to 90 years. Mean systolic and diastolic BP were $151 \pm 12.8 \mathrm{mmHg}$ and $90 \pm 14.6 \mathrm{mmHg}$ respectively. The clinical characteristics of the study population are as shown in Table 1 . The prevalence of each of the five ATP III criteria for the diagnosis of MS is as shown in Table 2. The criteria with the highest prevalence were increased waist circumference $105(43.8 \%)$ while the lowest was that of impaired fasting blood sugar 18(7.5\%). Type II DM was however found in $85(35.8 \%)$. Low HDL $-\mathrm{C}$ was found in $79(33 \%)$, while high TG was found in $58(24.2 \%)$.In addition the prevalence abdominal obesity (increased waist circumference) and impaired fasting glucose were significantly higher in women compared to $\operatorname{men}(\mathrm{P}=<$ 0.05).

The prevalence of MS was highest in those aged $45-$ 60 years and lowest for those aged less than 30 years. The prevalence of MS among different age groups with and without MS is shown in Table 3. 
Table 1: Clinical characteristics of the hypertensive patients

\begin{tabular}{lcccc}
\hline Parameter & All patients & Male & Female & P - value \\
\hline $\mathrm{SBP}(\mathrm{mmHg})$ & $151 \pm 12.8$ & $157 \pm 15.6$ & $149 \pm 14.2<0.001^{*}$ & \\
$\mathrm{DBP}(\mathrm{mmHg})$ & $90 \pm 14.6$ & $92 \pm 15.1$ & $90 \pm 16.2 \mathrm{NS}$ & \\
$\mathrm{FBG}(\mathrm{mmol} / \mathrm{L})$ & $6.1 \pm 3.3$ & $5.8 \pm 2.1$ & $6.0 \pm 3.2 \mathrm{NS}$ & \\
$\mathrm{HDL}-\mathrm{C}(\mathrm{mmol} / \mathrm{L})$ & $13.8 \pm 1.4$ & $1.36 \pm 1.2$ & $1.38 \pm 1.4$ & $\mathrm{NS}$ \\
$\mathrm{TG}(\mathrm{mmol} / \mathrm{L})$ & $1.72 \pm 0.83$ & $1.70 \pm 0.6$ & $1.74 \pm 0.8$ & $\mathrm{NS}$ \\
$\mathrm{WC}(\mathrm{cm}) 94.6 \pm 12.9$ & $92.2 \pm 10.9$ & $97.9 \pm 12.6$ & $0.001^{*}$ & \\
\hline
\end{tabular}

Key: * $P$ value statistically significant, NS; not significant, SBP; systolic blood pressure, DBP; diastolic blood pressure, FBG; fasting blood glucose, HDL - C; high density lipoprotein cholesterol, TG; triglycerides, WC; waist circumference.

Table 2: Prevalence of each of the criteria for diagnosis of metabolic syndrome among study population

\begin{tabular}{lcccc}
\hline Criteria & Total Subjects n(\%) & Males n(\%) & Females n(\%) & P - value \\
\hline Low HDL - C & $79(33)$ & $42(53.2)$ & $37(46.8)$ & NS \\
Elevated TG & $58(24.2)$ & $28(48.3)$ & $30(51.7)$ & NS \\
Increased WC & $105(43.8)$ & $38(36.2)$ & $67(63.8)$ & $<0.001^{*}$ \\
Type II DM & $85(35.8)$ & $45(52.9)$ & $40(47.1)$ & NS \\
Impaired FBG & $18(7.5)$ & $6(33.3)$ & $12(66.7)$ & $<0.001^{*}$ \\
\hline
\end{tabular}

Key: * $\mathrm{P}$ value statistically significant, NS; not significant, $\mathrm{HDL}-\mathrm{C}$; high density lipoprotein cholesterol, TG; triglycerides, WC; waist circumference, DM; diabetes mellitus, FBG; fasting blood glucose.

Table 3: Prevalence of metabolic syndrome by age

\begin{tabular}{lccc}
\hline Age group & Total & With MS & Without MS \\
\hline$<30$ & 24 & 4 & 20 \\
$31-44$ & 57 & 22 & 35 \\
$45-60$ & 89 & 40 & 49 \\
$>60$ & 26 & 26 & 44 \\
Total & 240 & 92 & 148 \\
\hline
\end{tabular}

Key: MS; metabolic syndrome.

\section{DISCUSSION}

Hypertension frequently clusters with other CVD risk factors, thus increasing the risk for MS. The prevalence of MS of $38.2 \%$ in this study is consistent with previous reports in Nigeria and other parts of the world (Charles et al., 2012; Burstein and Mortin 1996; Ulasi et al., 2010; Kelishadi et al., 2005; Li et al., 2009; Sorhhou et al.,
2004; Mule et al., 2005).Much higher rates were however reported in Spain (52\%), United States (62.9\%) and Jordan (52\%) (Barros et al., 2007; Ford et al., 2002; Yasein et al., 2010).The possible explanations for the variations may be explained by the genetic disparities, ethnic, socio demographic characteristics, lifestyle, duration of hypertension and experiences with treatment (Grundy et al., 2008; Misra et al., 2008; Saad 
et al., 1991). Black Africans are known to have lower adipose tissue mass for same BMI than Caucasians (Deurenberg et al., 1998).The finding of significantly higher prevalence of MS among Caucasian and Hispanic men than in their Black counterparts in the Third United States National Health and Nutrition Evaluation Study (NHANES III), suggests ethnicity may be important in determining the rate of MS (Ford et al., 2002). In Abuja, Nigeria however, a lower rate of $16.8 \%$ was reported (Orji et al., 2012). The differences in the criteria used in diagnosis may partly explain the observed difference.

The prevalence of MS was higher among females, a finding consistent with several reports among different populations (Burstein et al., 1996; Ulasi et al., 2010; Yasein et al., 2010; Kelliny et al., 2008). The higher prevalence among women may be due higher prevalence of obesity among women, and also the relatively sedentary life style of women in this part of the world, from socio cultural barriers in which women do not engage in work related physical activities. A few studies however reported equal prevalence between gender and even a male preponderance, which may be probably, due to different methodologies( Alegria et al., 2005; Ohta et al., 2007; Badr et al., 2007; Abu et al., 2008; Fezeu et al., 2007).

Central obesity was the most prevalent component of MSpresent in the participants. This finding has been reported in previous studies (Ulasi et al., 2010; Kelliny et al., 2008; Fezeu et al., 2007).In addition, Fezeu et al, in Cameroon reported that central obesity was more highly associated with components of MS than was homeostasis model assessment for insulin resistance (HOMA - IR), and went further to conclude that central obesity was likely to be the key determinant of MS in sub Saharan Africa (Fezeu et al., 2007).

The prevalence of MS has been reported in numerous studies to increase with age (Ford et al., 2002; Morimoto et al., 2008; Yi et al., 2010).In the present study, prevalence of MS was higher among older adults aged $\geq$ 40 years. This is attributed to the fact that ageing is associated with emergence of insulin resistance and diversion of fat from peripheral to central sites (Boden et al., 1993). In addition, neurohomonal alterations associated with ageing can predispose, promote and enhance pathogenesis of MS. The age related loss of body fat may be responsible for the decline in MS rate among the oldest groups (Boden et al., 1993).

\section{CONCLUSION}

Metabolic syndrome is highly prevalent among hypertensive subjects. The clustering of other CVD risk factors with hypertension makes them at risk of developing MS.
Therefore, these individuals should be routinely screened and have these risk factors corrected through initiation of lifestyle and other treatment measures, in order to prevent them from developing cardiovascular disease.

\section{REFERENCES}

Abu Siddique MA, Sultan MA, Haque KM, Zaman MM, Ahmed CM, Rahim MA (2008). Clustering of metabolic factors among patients with essential hypertension. Bangladesh Med Res Counc Bull.; $34: 71-5$.

Albeti KG, Eckel RH, Grundy SM (2009). Harmonizing the metabolic syndrome: a joint interim statement of the International Diabetes Task Force on Epidemiology and Prevention; National Heart, Lung and Blood Institute; American Heart Association; World Heart Federation; International Artherosclerosis Society; and International Association for the study of Obesity. Circulation; 120: 1640-45.

Albeti KG, Zimmet P, Shaw J (2006). Metabolic syndrome - a new world wide definition. A concensus statement from the Intl. Diabetes Federation. Diabet Med; 23: 469 - 80.

Alegria E, Cordero A, Laclautra M, Grima A, Cassanovas JA (2005). Prevalence of metabolic syndrome in the Spanish working population. MESYAS Registry. Rev EspCardiol.; 58: 797 - 806.

Badr $\mathrm{HE}$, Al Orifan FH, Amasha MM, Khadadah KE, Younis $\mathrm{HH}$, Saedah MA (2007). Prevalence of metabolic syndrome among healthy Kuwaiti adults: primary health care centres based study. Middle East J Family Med.; 5: 30 - 6.

Balkau B, Charles MA (1999). Comment on the provisional report from 'The WHO consultation.' European Group for the study of Insulin Resistance (EGIR) Diabet Med; 16: 442 - 3.

Barros V, Escobar C, Calderon A, Listerri JI, Alegria E, Muniz J Prevalence of the metabolic syndrome in patients with hypertension treated in general practice in Spain: An assessment of blood pressure and low density lipoprotein cholesterol control and accuracy of diagnosis. J Cardiometab Syndr. 2007; 2: $9-15$.

Berner A, Lestringant GG, Nyomba BL, Frosard P, Saadi H (2006). Acanthosisnigricans, hyperinsulinaemia and risk factors for cardiovascular disease. East Mediterr Health J; $6: \mathrm{H} 416-\mathrm{H} 424$.

Boden G, Chen X, DeSantis RA, Kendrick Z (1993). Effect of age and body fat on insulin resistance in healthy men. Diabetes Care; 16: $728-33$.

Burstein M, Mortin R (1996). Quantititative determination of HDL cholesterol using the enzymatic colorimetric method. Life Sci; 8 : $345-7$.

Charles UO, Emeka GO (2012). Prevalence and characteristics of metabolic syndrome among newly diagnosed hypertensive patients. Indian J Endocrinol and Metab; 16: S104 - S109.

Daubresse JC. The importance of syndrome $X$ in daily practice. Rev Med Brux2000; 21: $473-477$.

Deurenberg P, Yap M, Van Staveren WA (1998). Body mass index and percent body fat: A meta-analysis among different ethnic groups. Int J Obes Rel Metab Disord; 22:1164 - 71.

Eihorn D, Reaven GM, Cobin RH (2003). American College of Endocrinology position statement on the insulin resistance syndrome. Endocr Pract; 9:237 - 52.

Fezeu L, Balkau B, Kengne A, Sobngwi E, Mbanya J. Metabolic syndrome in sub Saharan African setting: Central obesity may be the key determinant. Artherosclerosis. 2007; 193: $70-60$.

Ford ES, Giles WH, Dietz WH. Prevalence of metabolic syndrome among US adults. Findings from the Third National Health and Nutrition Examination Survey. JAMA. 2002; 287: 356 - 9.

Grundy SM (2008). Metabolic syndrome pandemic. Arterioscler Thromb Vasc Biol; 28: 629 - 36.

Grundy SM, Brewer FI, Cleeman JI (2004). Definition of metabolic syndrome: report of the National Heart, Lung and Blood Institute 
American Heart Association conference on the scientific issues related to definition. Circulation; 109: $433-8$.

Grundy SM, Cleeman JI, Daniels SR, Donato KA, Eckel RH, Francklin BA (2005). Diagnosis and management of metabolic syndrome: An American Heart Association / National Heart, Lung and Blood Institute scientific statement . Circulation; 112: $2735-52$.

Kelishadi R, Derakhshan R, Sabet B, Saraf- Zadegan N, Kahbazi M, Sadri GH (2005). The metabolic syndrome in hypertensive and normotensive subjects: The Isfahan Healthy Heart Programme. Ann Acad Med Singapore.; 34; $243-9$.

Kelliny C, William J, Reiesen W, Paccaud F, Bovet P (2008). Metabolic syndrome according to different definitions in a rapidly developing country of the African region. Cardiovasc Diabetol.; 7; 27.

Li WJ, Xue H, Sun K, Song XD, Wang YB, Zhen YS (2009). Cardiovascular risk and prevalence of metabolic syndrome by differing criteria. Chin Med J (Engl); 121: 1532 - 6.

Miranda PJ, Defronzo RA, Califf RM, Guyton JR. Metabolic syndrome: definition, pathophysiology and mechanisms. Am J Heart 2005; 149: $33-45$.

Misra A, Khurana L (2008). Obesity and the metabolic syndrome in developing countries.J Clin Endocrinol Metab.; 93: S29 - 30.

Morimoto A, Nishimura R, Suzuki N, Matsudaira T, Taki K, Tsujino D (2008). Low prevalence of metabolic syndrome and its component in rural Japan. Tohoku J Exp Med.; 216: 69 - 75.

Mule G, Nardi E, Cottone S, Cusimano P, Volpe V, Piazza G (2005). Influence of metabolic syndrome on hypertension related target organ damage. J Intern Med.; 257: 503-13.

National Cholesterol Education Programme. Third report of the expert panel on the detection, evaluation and treatment of high blood cholesterol in adults (Adult treatment Panel III) National Heart Lung and Blood Institute, National Institute of Health. NIH Publication No. 02 - 5215. 2002: 3163 - 3184.

Ohta Y, Tsuchashi T, Arakawa K, Onaka U, Ueno M (2007). Prevalence and lifestyle characteristics of hypertensive patients with metabolic syndrome followed up at an outpatient clinic in Fukuoka, Japan. Hypertens Res; 30: 107782.
Ojji DB, Ajayi SO, Mamven MH, Alabo P (2012). Prevalence of metabolic syndrome among hypertensive patients in Abuja, Nig. Ethn Dis.; 22: 1- 4.

Perry IJ, Wannamethee SG, Walker MK, et al. Prospective study of risk factors for development of non - insulin dependent diabetes in middle aged British men.BMJ 1995; 310: 560 - 564.

Saad MF, Lillioja S, Nyomba BL, Castillo C, Ferrara R, De Gregorio M (1991). Racial differences in the relation between blood pressure and insulin resistance. N Eng J Med.; 324: $733-9$

Sorhhou El, Al - Quallaf B, Al Namash HA, Ben Nakhi A, Al Batish MM, Habiba SA (2004). Prevalence of metabolic syndrome and target organ damage in untreated essential hypertensives. J Hypertens; 22: $1991-8$.

The expert committee on the Diagnosis and classification of Diabetes Mellitus: Report of the expert committee on the Diagnosis and Classification of Diabetes Mellitus. Diabetes Care 2002; 25: S5 S20.

Ulasi II, ljoma CK, Onodugo OD (2010). A community based study of hypertension and cardio metabolic syndrome in semi urban and rural communities in Nigeria.BMC Health Ser Res; 10: 71.

World Health Organization (WHO) Non - communicable diseases country profiles 2011, 'WHO Global Report, Geneva, Switzerland, September 2011, http://whqlibdoc.who.int/publications/2011/978924 1502283.eng.pdf.

Yasein N, Ahmad M, Matrook F, Nasir L, Froelicher ES (2010). Metabolic syndrome in patients with hypertension attending a family practice clinic in Jordan. East Mediterr Health J; 16: 375 - 80.

Yi Z, Jing J, Xiu - ying L, Hongxia X, Jiajum Y, Yuhong Z (2010). Prevalence of the metabolic syndrome among rural original adults in Ning Xia, China. BMC Public Health; 10: $140-45$. 